\title{
Genetic variability, correlation, path analysis and construction of selection index in mulberry silkworm, Bombyx mori L. I. Genetic variability
}

\author{
Md. Ariful Hasan, Sawdagar Mahfuzar Rahman, and Md. Kamrul Ahsan \\ Department of Zoology, Rajshahi University, Rajshahi-6205, Bangladesh
}

\begin{abstract}
The genotypic variability and heritability for nine quantitative characters in 65 varieties of silkworm, B. mori L. have been investigated. Variation among genotypes were highly significant $(p<0.001)$ for all the characters indicating the existence of a real difference among the genotypes which are suitable for breeding purposes. The highest heritability was obtained for shell weight followed by filament size (FS), filament length (FL), expected cocoon yield out of $100 \mathrm{dfls}(\mathrm{ECY})$, surviving percentage of larvae (SPL), cocoon weight $(\mathrm{CW})$, egg hatching percentage (EHP) and mature larval weight (MLW). Comparatively high heritability accompanied by a genetic advance was recorded for FL and total number of eggs laid per female (TEL) indicating the importance of additive gene effects of these characters, but shell weight, cocoon weight and filament size showed high heritability and low genetic advance indicating the involvement of nonadditive gene systems in the inheritance of these characters. So selection on the basis of these characters, with relatively more emphasis upon filament length and total number of eggs laid per female to obtain high yielding varieties of $B$. mori is suggested.
\end{abstract}

Key words: Genetic variability, Bombyx mori.

\section{Introduction}

Selective breeding is aimed at improving the existing ones and developing new breeds and hybrids which is essentially a creative process and is dependent on the study of genetic parameters and genetic architecture forming a basis for most appropriate selection scheme. Consequently, success in any breeding programme for evolving superior breeds depends on the selection of parental material on the basis of their genetic variability, geographical distribution and per'se performances and some physio-morphological characters is essential (Akanda et al., 1998). To get idea of the genetic variability existing among the varieties with regard to the quantitative characters of economic importance it becomes necessary to apply appropriate method of biometrical analysis. The concept of multiple gene inheritance of quantitative traits is now one of the most important principles of genetics which require refined statistical method. Smith (1944) proposed polygenic concept of quantitative characters and Mather (1949) on the basis of this concept detailed Fisher's (Fisher et al., 1932) statistical method to study genetic components of variance as well as environmental variance.

In silkworm quantitative character is jointly controlled by multiple genes and environmental factors (Reza \& Rahman, 2005; Zhao et al., 2007; Ahsan \& Rahman, 2008). So the yield potential of $B$. mori needs to be improved through an effective breeding programme. But very diminutive concentration has so far been given for the improvement of the mulberry silkworm, Bombyx mori L. in Bangladesh (Reza \& Rahman, 2005; Ahsan et al., 2010).
Studies were therefore, undertaken to estimate the genetic variability, heritability and genetic advance for some important quantitative characters and correlations among them at phenotypic and genotypic levels of $B$. mori.

\section{Materials and Methods}

The material for the present investigation comprised of 65 multivoltine (indigenous, developed and exotic) and bivoltine (developed and exotic) varieties of mulberry silkworm $B$. mori. The names of the varieties are listed in Table-1.

The eggs of these varieties were brushed (3dfls for each genotype) in a randomized design with three replications each. The rearing was conducted in the rearing house No. 2 of the Bangladesh Sericulture Research and Training Institute, Rajshahi. Scientific technology of silkworm rearing was followed according to Krishnaswami (1978) and Rahman (1983). Data recorded for this study were: total number of eggs laid per female (TEL), egg hatching percentage $(E H P)$, mature larval weight (MLW), surviving percentage of larvae (SPL), cocoon weight (CW), shell weight (SW), length of filament (FL), filament size (FS) and estimated cocoon yield out of 100 dfls (ECY). Genotypic $\left(\delta^{2} g\right)$ and phenotypic $\left(\delta^{2} p\right)$ variations were estimated by the formula given by Burton \& De Vane (1953) and the coefficient of variability was worked out as described by Burton (1952). Heritability in broad sense was estimated by the following formula given by Hanson et al. (1956). 
Table-1. Varieties of Bombyx mori L. used in the experiment.

\begin{tabular}{lllll}
\hline 1. Nistari & 14. BSR-3 $(\mathrm{p})$ & 27. BSR-95/10(P) & 40. Bipul & 53. Ziangsu (P) \\
2. Nistari (P) & 15. BSR-3 $(\mathrm{m})$ & 28. BSR-95/14(P) & 41. BSRI-83/1 & 54. Dong 34(M) \\
3. Nistari (M) & 16. BSR-10 (m) & 29. BSR-95/22(P) & 42. BSRI-83/2 & 55. Dong 34 (P) \\
4. Nistari L & 17. Nistid white (P) & 30. BSR-98/1(P) & 43. BSRI-83/3 & 56. BV (M) \\
5. Nistari G & 18. BSR-JB & 31. BSR-98/2(P) & 44. BSRI-85/1 & 57. BV (P) \\
6. ISK & 19. BSR-IM(P) & 32. BSR2000/1(GM) & 45. BSRI-85/2 & 58. RB (M) \\
7. MBY- 011S (P) & 20. BSR-(GL) & 33. BSR-02/1(M) & 46. BSRI-85/3 & 59. RB (P) \\
8. BN P & 21. BSR-92/2(P) & 34. BSR-02/2(P) & 47. BSRI-J & 60. RB-001 (M) \\
9. BN (M) & 22. BSR-92/5(P) & 35. BSR-02/3 & 48. Urboshi-1 & 61. RB-001 (P) \\
10. NN-7B (P) & 23. BSR-92/7(P) & 36. BSR-03/1 & 49. Urboshi-4 & 62. RB-111 \\
11. NM-7B (M) & 24. BSR-92/8(P) & 37.BSR-03/2 & 50. BSRI-801 & 63. RB-112 \\
12. BSR-1 white $(p)$ & 25. BSR-92/14(P) & 38. O5 & 51. BSRI-802 & 64. RB-SB (M) \\
13. BSR- white $(m)$ & 26. BSR-92/16(P) & 39. R $\mathrm{S}_{1}$ & 52. Ziangsu 12-J & 65. RB-SP (P) \\
\hline
\end{tabular}

Heritability (Broad sense) $=\sigma^{2} g / \sigma^{2} \times 100$

The expected genetic advance was stimated by the following formula:

Genetic advance (GA) $=\sigma^{2} g / \sigma^{2} p \times k \sqrt{ } \delta^{2} p$.

Where $k$ has a value of 2.06 which is the expectation in $5 \%$ selection intensity from a large population (Lush, 1949; Miller et al., 1958)

\section{Results and discussion}

An analysis of variance showed that the item, genotype was highly significant for all the characters studied indicating that the varieties possess a wide range of genetic diversity and these materials are suitable for breeding purposes (Table 2.). Varietal differences with respect to egg, larval and cocoon characters in B. mori have been reported by Ahsan et al. (2000). Similar results on varietal diversity have also been substantiated by the findings of Pershad et al. (1986), Govindan et al. (1987), Toyade (1987), Reza \& Rahman (1996), Ahsan \& Rahman (2008) and Ahsan et al. (2010). Results on overall range, mean with standard error and genetic variability for different characters have been presented in Table 3 . Phenotypic variances $\left(\sigma^{2} p\right)$ were generally greater than their corresponding genotypic $\left(\sigma^{2} g\right)$ or environmental variances $\left(\sigma^{2} e\right)$ in all the cases. Closer values of $\sigma^{2} p$ and $\sigma^{2} g$ as well as higher values of $\sigma^{2} g$ than $\sigma^{2} e$ for all the characters implied that the major portion of the phenotypic variation was of genotypic in nature.

Phenotypic $\left(\mathrm{CV}_{\mathrm{p}}\right)$, genotypic $\left(\mathrm{CV}_{\mathrm{g}}\right)$ and environmental $\left(C V_{e}\right)$ co-efficient of variability, heritability $(\mathrm{H})$, genetic advance (GA) and genetic advance as percentage of mean (GA\%) were estimated and presented in Table 4. The maximum phenotypic and genotypic co-efficient of variation was found in SW and the minimum in EHP whereas the highest environmental coefficient of variation was recorded in FL and the lowest in SW. The genotypic coefficient of variation alone is not sufficient to determine the amount of variation which is heritable. The heritable portion of variation can be found from heritability estimates and genetic gain. In this study, SW, ECY, FL and TEL showed very high heritability together with high phenotypic $\left(\mathrm{CV}_{\mathrm{p}}\right)$ and genotypic $\left(\mathrm{CV}_{\mathrm{g}}\right)$ coefficient of variability. On the other hand, FS, SPL and CW showed very high heritability but moderate phenotypic and genotypic coefficient of variability together with low environmental coefficient of variability. Ahsan \& Rahman, (2008) reported high heritability together with high phenotypic and genotypic coefficient of variability of total eggs laid by female. The result of Ahsan et al. (2010) is similar with the present findings who reported a high heritability coupled with high phenotypic and genotypic coefficient of variability for $F L$ and ECY.

In the present experiment the highest heritability was obtained for SW followed by FS, FL, ECY, SPL, CW, EHP and MLW. But very low heritability for $\mathrm{CW}$ and for silk richness was reported by Nassirillaev \& Abbasov (1980). Similar low values of heritability were also noted by Tsocheva (1981) who investigated relationship between cocoon length versus diameter. Ozdzesska \& Kremky (1987) also noticed a very high heritability value for hatching percentage and survival rate; however, they found a very low value for filament length, cocoon weight and shell weight. 
Table 2. Analysis of variance for nine quantitative characters in B. mori.

\begin{tabular}{llllllllll}
\hline Item (df) & \multicolumn{1}{c}{ F-value } \\
\cline { 2 - 10 } & TEL & EHP & MLW & SPL & CW & SW & FL & FS & ECY \\
\hline Within Varieties (64/128) & $223.56^{*}$ & $38.08^{*}$ & $16.47^{*}$ & $125.91^{*}$ & $96.51^{*}$ & $619.60^{*}$ & $157.72^{*}$ & $185.15^{*}$ & $132.41^{*}$ \\
Within Repplication (2/128) & 1.32 & 0.07 & 0.13 & 0.52 & 0.39 & 1.63 & 0.69 & 2.06 & 0.02 \\
\hline
\end{tabular}

${ }^{*} P<0.01$

Table 3. Range, mean with S. E. and component of variance of different characters of Bombyx mori.

\begin{tabular}{lcrrrr}
\hline Characters & \multicolumn{1}{c}{ Range } & Mean \pm S E & \multicolumn{1}{c}{$\sigma^{2} p$} & \multicolumn{1}{c}{$\sigma^{2} \mathrm{~g}$} & \multicolumn{1}{c}{$\sigma^{2} \mathrm{e}$} \\
\hline TEL & $309.30-699.37$ & $477.81 \pm 8.470$ & 8093.890 & 7986.24 & 107.650 \\
EHP & $80.13-97.87$ & $91.03 \pm 0.980$ & 19.130 & 17.700 & 1.430 \\
MLW & $2.16-3.96$ & $2.99 \pm 0.140$ & 0.180 & 0.150 & 0.030 \\
SPL & $60.29-99.94$ & $84.22 \pm 1.140$ & 83.620 & 81.660 & 1.960 \\
CW & $0.9000-1.6200$ & $1.28 \pm 0.020$ & 0.031 & 0.030 & 0.001 \\
SW & $0.1042-0.2960$ & $0.17 \pm 0.002$ & 0.002 & 0.002 & 0.000 \\
FL & $347.30-792.70$ & $577.89 \pm 12.770$ & 13027.700 & 12783.01 & 244.690 \\
FS & $1.44-2.88$ & $2.20 \pm 0.030$ & 0.080 & 0.080 & 0.000 \\
ECY & $19.99-46.05$ & $32.69 \pm 0.820$ & 44.650 & 43.650 & 1.000 \\
\hline
\end{tabular}

$\sigma^{2} p$ : Phenotypic variance; $\sigma^{2} g$ : Genotypic variance; $\sigma^{2} \mathrm{e}:$ Environmental variance.

Table 4. Phenotypic $(C V p)$, genotypic $(C V g)$, environmental $(C V e)$, cofficient of variation, heritability $(H)$, genetic advance (GA) and genetic advance as percentage of mean (GA\%) of different characters of Bombyx mori.

\begin{tabular}{lcccccc}
\hline Characters & CVp & CVg & CVe & H & GA & GA\% \\
TEL & 18.83 & 18.70 & 4.75 & 98.67 & 182.87 & 38.27 \\
EHP & 4.81 & 4.62 & 1.25 & 92.51 & 8.34 & 9.16 \\
MLW & 14.00 & 12.82 & 0.98 & 83.75 & 0.72 & 24.16 \\
SPL & 10.86 & 10.73 & 1.53 & 97.65 & 18.40 & 21.84 \\
CW & 13.76 & 13.55 & 0.27 & 96.95 & 0.35 & 27.48 \\
SW & 24.66 & 24.60 & 0.07 & 99.51 & 0.08 & 50.57 \\
FL & 19.75 & 19.56 & 6.50 & 98.12 & 230.71 & 39.92 \\
FS & 12.87 & 12.77 & 0.24 & 98.40 & 0.58 & 26.09 \\
ECY & 20.44 & 20.21 & 1.75 & 97.77 & 13.46 & 41.17 \\
\hline
\end{tabular}

Filament length and TEL expressed the highest genetic advance together with high heritability. It indicated the importance of additive gene effects of these characters (Rahman, 1984; Reza et al., 1993; Ahsan et al., 2010). SW, CW and FS exhibited high heritability and low genetic advance, suggesting limited scope for manipulation of these characters. These could be due to non-additive gene action which includes dominance and epistasis (Ahsan \& Rahman, 2008). In such situations progeny testing and a recurrent selection might be helpful to improve these traits (Rahman, 1984; Rao, 1997; Ahsan et al., 2000; Ahsan \& Rahman, 2010). Here SPL and ECY showed high heritability and moderate genetic advance. Sen et al. (1995) had also shown high heritability and moderate genetic advance for MLW and CW in multivoltine silkworms. Reza et al. (1993) and Reza \& Rahman
(1996) found a non-additive component of genetic variation as an important feature of some larval and cocoon characters in B. mori. Govindan et al. (1987) also found a non-additive component of genetic variation as an important feature of some larval and cocoon characters in B. mori. Kantaratanakul et al. (1987) reported in favour of additivity with respect to filament length.

\section{Reference}

Ahsan, M.K. \& Rahman, S.M. 2010, Genetic variation of some quantitative traits in ten exotic varieties of silkworm, Bombyx mori L., Univ. J. Zool. Rajshahi Univ. 29: 69-71.

Ahsan. M.K. \& Ramian, S.M. 2008. Genetic variability and correlation analysis in hybrids of silkworm, Bombyx mori L. for egg characters. Univ. J. Zool. Rajshahi Univ. 27: 13-16. 
Ahsan, M.K., Rammn, S.M. \& All, I.A. 2000. Variability of some quantitative traits in the hybrids of silkworm, Bombyx mori L. Univ. J. Zool. Rajshahi Univ. 19: 20-24,

Ahsan. M.K., Rahman, S.M. \& Haque, M.T. 2010. Genetic variability, heritability and correlation analysis for some characters ill hybrids of the mulberry silkworm, Bombyx mori L. J. Life Earth Sci. 5: 43-46.

Akmida, N/I.A.L., Alam, M.S. \& Uddin, M.N. 1998. Genetic variability, correlation and path analysis in Composite maize, Bangladesh J. Agric. Res. 23(1): 107-113.

Burton, G.W. 1952. Quantitative inheritance in grass. Proc. $6^{\text {th }}$ Inter. Grassland Cong. 1, 277- 283.

Burton, G.W. \& Devane, E.M. 1952. Estimating heritability in tall fescue, Eestuca arundinaces. From replicated clonal material. Agron, J. 45: 478-481.

Fisher. R.A., Immer, F.R. \& Tendin, O. 1932. The genetical interpretation of statistics of the third degree in the Study of quantitative inheritance. Genetics 17: 107-124.

Govindan, R., Magadum, S.B. \& Satenahalli, S.B. 1987, Breeding with some polyvoltine and blvoltinc stains of the silkworm, Bombyx mori L. Sericologia, 27: 597-604.

Rahman, C.H., Robinson, H.F. \& Comstock, R.E. 1956. Biometrical studies of yield in segregation populations of Korean lespedeza. Agron. J. 48: 268-272.

Johnson, H.W., Robinson, H.F. \& Comstock, R.E. 1955. Estimates of genetic and environmental variability in soybeans. Agron. J. 47: 314-318.

Kantaratanakul, S., Tharvornanulkit, C., Wongthmig, S., Charconying, S., Compiranon, A., \& Saksoong, P. 1987. Heterosis in F1 hybrid between polyvoltine and bivoltine silkworm (Bombyx mori L) Sericologia. 27: 373- 380.

Krishaswami, S. 1978. New Technology of silkworm rearing. Central Silk Board, India. 23pp.

Lush, J.L. 1949. Heritability of quantitative characters in farm animals Proc. $8^{\text {th }}$ Int. Contr. Genet, Suppl. Hereditas. 356-375.

Mather, K. 1949. Biometrical Genetics, Dover Publication, New York, 282pp.

Miller, P.A., Williams, J.C., Robinson, H.F. \& Comstock, R.E. 1958, Estimates of genotypic and environmental variances and covariance's in up land cotton and their implication in selection. Agron. J. 50: 126-131.

Nassirillaev, U.N. \& Abbasov, B.G. 1980. Opcenka addi tivnoi I neadditiv noi nasleduyemosti khozyayjstve nuo-cennych prizna kovto tovogo shelko-pryada maosnove polyallclnych sparivanyi sheik. 91(4): 10-11.

Ozdzenska, B. \& Kremky, J. 1987. Estimation of heritability and genetic, phenotypic and environmental correlations in outbreed population of mulberry silkworm, Bombyx mori, L. Sericologia 27: 633-639.

Pershad, G.D., Datta, R.K., Bhargava, S.K., Kumar, H.V. \& Jolly, M.S. 1986. Combining ability analysis in multivoltine races of Bombyx mori $\mathrm{L}$. Sericologia. 26: 307-315.

Petkov, N. \& Yolove, A. 1979. Influence of cocoon size and weight on heterosis effect in silkworm Bombyx mori L., Geneti. Sel. 12: 286-291.

Petkov, N. \& Yolove, A. 1980. The problem of genotype-environment interaction and inheritance of some characters of' Bombyx mori L. II. Effect of the seasons of silkworm feedings. Genet. \& Plant Breed, 13(I): 62-66.

Rahman, S.M. 1983. Technology of mulberry silkworm rearing suitable for the climatic condition in Bangladesh, Reshom 1: 71-79.

Rahman, M. S. 1984. Studies on the genetic improvement off' eri silkworm, Philosamia ricini. Boised of Bangladesh, Ph.D. thesis Department of' Zoology, Rajshiahi University. 419pp.

Rao, P.R.T. 1997. Genetic architecture and gene action in Bombyx mori L. Ph.D. thesis. Department of Zoology, North Bengal University, India. I191pp.

Reza, A.M.S. \& Rahman, S.M. 1996. The genetic variability, heritability and genetic advance in silkworm, Bombyx mori L. Bangladesh. J. Agile. 21: 1-6.

Reza. A.M.S. \& Rahman, S.M. 2005. Genetic parameters of some yield and yield contributing traits in silkworm, Bombyx mori L. Univ. J. Zool. Rajshahi Univ. 24: 55-58.

Reza. A.M.S, Rahman, M.S. \& Rahman, S.M. 1993. Studies on the variation of some larval traits in different breeds of silkworm, Bombyx mori L. Univ. J. Zool. Rajshahi Univ. 12: 21-24.

Sen, S.K., Das, S.K., Rao, P.R.T., Ghosh, B., Das, N.K., Chattopadhaya, S., Roy G.C. \& Sinha, S.S. 1995. Studies on some important genetic parameters in silkworm Bombyx mori L. Indian J. Genet. 55(3): 238-242.

Smith, H.H. 1944. Recent studies on the inheritance of quantitative characters in plants. Bol. Rev. 10: 349-382.

Tayade, D.S. 1987. Heterosis effect of economic traits of new hybrids of silkworm, Bombyx mori L. Marathwada conditions. Sericologia. 27(2): 301307.

Tsocheva. K. 1981. Genetic structure of out breeding and inbreeding Bombyx mori. L. Populations concerning the index of' the cocoon. Genet. \& Phall Breed. .14: 379-385.

Zhao, Y., Chen, K. \& He,. S. 2007. Key principles for breeding spring-and-autumn using silkworm varieties: from our experience of' breeding 873×874. Caspian J. Environ. Sci. 5: 57-61. 